paper on the physiology and pathology of cases of paralysis of the several factors concerned in articulation, deglutition, and vocalisation. Cases of the greatest interest are those in which the paralysis is of but one side-viz., of half the tongue, of the same half of the palate, and of one vocal cord. I believe, however, that the orbicularis oris when it suffers is always affected on both sides, or, I suppose I should say, all round.

Manchester-square, $w$.

\section{ON FIBROUS POLYPUS OF THE NOSE, WITH PARTICULARS OF A CASE AND OPERATION.}

BY GEORGE LICHTENBERG, M.D.,

SURGEON TO THE GERMAN HOSPYTAL, AND TO THE TRAINING HOSPITAL, TOTTHNHAM.

Among the varied number of surgical diseases of the nose, those which are comprised under the name of polypus are almost of daily occurrence in the out-patient department of a hospital surgeon. The medical student will there have ample opportunities of seeing that polypus which generally goes under the name of the mucous or gelatinous polypus, and he can watch its removal either by the forceps, or by simple ligature, or by $\mathrm{Mr}$. Hilton's in. geniously constructed snare, and by different other ways, and at the same time will find, by experience, that in many instances its removal has given the death-blow to the disease, but in many others that it is also liable to recur, when again its removal must be undertaken in one or the other way. But even should it recur, although the patient may find it again troublesome, he will, after all, at least in most cases (Mr. Ure mentions a case of necrosis), not seriously suffer from this complaint, and be tolerably sure at last to be finally cured of it without any impairment of his general health.

But there is another kind of polypus which the medical student will perbaps bave no opportunity of seeing during his hospital career, and if so, certainly not many cases-I mean the fibrous polypus. Its name already shows its principal nature, and I therefore shall not further comment upon it. The flbrous polypus is, with regard to the patient, a much more serious complaint than the mucous or gelatinous one; nay, it may become a very formidable disease. Its general seat is the periosteum, or, to be more correct, the fibrous layer of the mucous membrane of the nasal fosse, or even the bone itself. It is much more vascular than the former one, of hard structure, and therefore very liable to displace during its growth the bony structures that are in its way, or to induce absorption of the same; and there are not instances wanting where this kind of new growth has found its way by this process even into the brain. If through an operation only partial removal has taken place, the disease is not only liable to recur with renewed violence, but very often to assume a malignant character and to prove rapidly fatal. If, on the other hand, however, the disease has not too far advanced, and the surgeon is enabled to remove the growth entirely, there is a chance of an entire cure. It is therefore of the utmost importance that the surgeon should not only make himself thoroughly acquainted with the actual seat of this complaint, but should also be able to remove by the operation, of whatever kind it may be, every vestige of the disease. But in order to achieve this it is necessary beyond everything to have a thorough access to the malady, and the surgeon therefore will find himself under the painful necessity of performing rather formidable operations-for those operations which require for this disease the complete or partial ablation of the upper jaw may with justice be called formidable,-and yet a frequent great disfigurement is preferable to a certain death ; and cases will occur where no other choice is left to the surgeon. But in many cases, and this is again a triumph of modern surgery, an osteoplastic operation (Langenbeck, Huguier), where the upper jaw is temporarily displaced and afterwards replaced, will serve the same object. A third method, by which we may gain access to the disease, consists in making an opening through the palate, an operation principally improved and recommended by Mons. Nélaton.

These three different kinds of operations, to which I merely wish to draw the attention of the reader in a cursory way, as every surgeon is well acquainted with them, are, however, only adapted to those cases which, on account of their size, do not allow of our performing a less severe operation-I mean those polypi which, although their original seat may bave been in the cavity of the nose, have afterwards formed other attachments-as, for instance, in the antrum Highmori,-or may also have sprung from the basilar process, or thereabout, and have formed that kind of new growth which is comprised under the name of naso-pharyngeal polypi. In these cases, I say, we shall of ten be obliged to perform one or the other of the abovementioned operations. If, on the other hand, the disease is still in its infancy, if, in other words, the polypus is still of a small size, then we have other and less severe means at our command to achieve our ohject. In many instances we shall be able simply to apply a ligature, without any great difficulty, round the base of the polypus, and thus remove it. But cases may occur where the surgeon will not be able to do this so easily, for even in cases of moderatesized polypi the simply mechanical widening of the nostril will often, on account of the particular attachment, not give us sufficient access to the disease, and different methods have therefore been proposed to attain more room for the accomplishment of the object. Without enumerating here the various kinds of operation, it may perhaps be not out of place to draw the attention of the profession to one particular kind, which, although first proposed and performed by Professor von Langenbeck more than twenty years ago, does not seem to be so generally known in this country as it deserves to be; and, as I had lately an opportunity of testing the great value of it, and at the same time followed entirely during the removal of the polypus Langenbeck's plan, I think I cannot do better than simply recount the manner in which I performed the operation.

E. V-, aged fifty-three, was admitted as an in-patient into the German Hospital on the 23rd of March last. The patient told me that about two years ago he felt a blocking up of the left nostril, which in the beginning he attributed to a simple cold. In the middle of last year he suffered more inconvenience from it, and he therefore sought advice at the German Hospital as an out-patient. Local applications were of no avail; and as Dr. Burger, under whose care he had been latterly, saw that he was suffering from a fibrous polypus, the thorough removal of which by placing a simple liugature around it could be of no avail, and it seemed impossible to reach the base either by the mouth or nostril, he advised him to become an in-patient in order to undergo another operation for the removal of the polypus. I examined the patient several times most carefully in conjunction with Dr. Burger, and came likewise to the conclusion that it would be utterly useless to undertake anything without previously gaining fuller access to the disease. The patient, whose nose was naturally rather broad, and showed no difference between its two sides, complained, however, occasionally of a dull kind of pain and great discomfort in the upper part of the left nostril, through which the passage of the air was wholly excluded. Upon inspection, I noticed high up in the left nostril a reddish-looking body, rather larger than a big cobnut. It was almost immovable, and seemed decidedly to possess a broad base, and was hard and elastic to the touch. It was impossible to define accurately the exact seat of the new growth, and examina. tion with the rhinoscope could give me no further clue. I therefore told the patient what I further intended to do, and readily gained his full permission to undertake any. thing that $I$ thought proper.

The patient was accordingly put under chloroform on April 3rd, and I commenced the operation by inserting the point of $\mathrm{my} k \mathrm{knife}$ in the middle of the glabella, and then, carrying the incision in a straight line downwards over the dorsum of the nose till I arrived at the ala, I made a sweep to the left and divided the skin, where the osseous and cartilaginous part of the nose join, down to the cheek. I then carefully dissected off the flap down to the bone, without, however, injuring the periosteum, and turned it aside, so that the left side of the nose down to the ala was entirely deprived of its integument. I next separated the left ala 
entirely from the osseous portion of the nose by passing my knife through the entire thickness of the cartilage, without, however, interfering in any other way with the ala itself. Then after having divided the periosteum over the entire length of the nasal bone as well, and at the same time as near as possible to the septum, as also over the nasal process of the maxillary bone near the cheek, I inserted a very fine-bladed saw (expressly made for this purpose by Messrs. Krohne and Sesemann) next to the septum into the nasal bone, and sawed gently through it upwards; and this I did likewise with the nasal process, beginning at the lower part, and ending nearly opposite the canthus internus of the eye. Having thus separated the nasal bone and nasal process from its side attachments, I then easily with the assistance of a small dressing forceps turned these parts upwards, just like the lid of a box, the parts themselves being kept together outside by the periosteum, and inside by the mucous membrane. I now had a good view of the nasal cavity, and fortunately also of the entire polypus, which seemed to be attached according to all appearance with a broad base to the superior turbinated bone, and very likely partly also to the horizontal plate of the ethmoid. On account of its very broad attachment I was unable to pull it much further down; but easily succeeded in passing a wire loop (Maisonneuve's écraseur) round it, and with some few strong twists in detaching it from its abode. Hæmorrhage did not occur. I was now enabled to examine the nasal cavity still more minutely, and my colleagues as well as myself came to the conclusion that nothing of the original polypus had remained behind; but on the inner side of the original seat of the disease-viz., on the horizontal plate of the ethmoid, quite independently, so far as I could judge, from the new growth which I had removed, were two or three suspicious-looking excrescences which I did not like to leave undisturbed. I therefore touched them repeatedly with strong nitric acid, hoping that I might destroy them in that way; time only will show whether I have succeeded. After convincing myself once more that no bleeding was going on, I replaced the bones, a proceeding which was easily accomplished, covered them with the flap, and applied very carefully thirteen fine silk sutures, placed over the whole a slight compress, and had the patient put to bed.

He passed a pretty comfortable night, and the wound looked exceedingly well early next morning; towards evening, however, just twenty-four hours after the operation, rather severe swelling set in, and Dr. Port, the then house-surgeon, thought it advisable to remove all the sutures, which was done without any harm, as the flap was everywhere perfectly united. Everything then went on very satisfactorily until the 12th of April-namely, the ninth day after the operation, when a small fluctuating swelling showed itself at the upper part of the otherwise entirely united wound. I opened it with a small puncture, and some few drops of pus were evacuated. This circumstance made me rather anxious, as I thought partial exfoliation of the bone might take place; but the small wound, having one day discharged a little more and the next day perhaps a little less, was entirely closed by the 23rd, on which day we could pronounce the wound perfectly healed, no exfoliation whatever having taken place, and the patient therefore could be discharged.

I have only further to add that the constitutional symptoms after the operation were of a very trifling character . feverish symptoms only manifested themselves in a slight degree on the first four days, the highest temperaturenamely, on the second night after the operation-only showing 101.4, and on the third and fourth days the temperature was in the morning even normal.

The accompanying illustrations are executed by $\mathrm{Mr}$. D'Alton; the one merely a copy from Dr. Greb's Atlas, which is attached to Professors von Pitha's and Billroth's "Handbuch der Allgemeinen und speciellen Chirurgie," may, I hope, elucidate the way in which the operation is done still more than a mere description can accomplish. The other drawing shows the patient himself exactly two months after the operation. I then took an opportunity of once more examining the nostril, and $I$ could detect nothing which made me suspect a recurrence of the disease. The air passed equally freely through both nostrils, and the patient declared himself perfectly well. I have seen him at a later date, and the scar on the middle and side of the nose is less conspicuous than the present illustration shows, and I am quite sure that in some few months' time there will be scarcely an outward trace left of any surgical

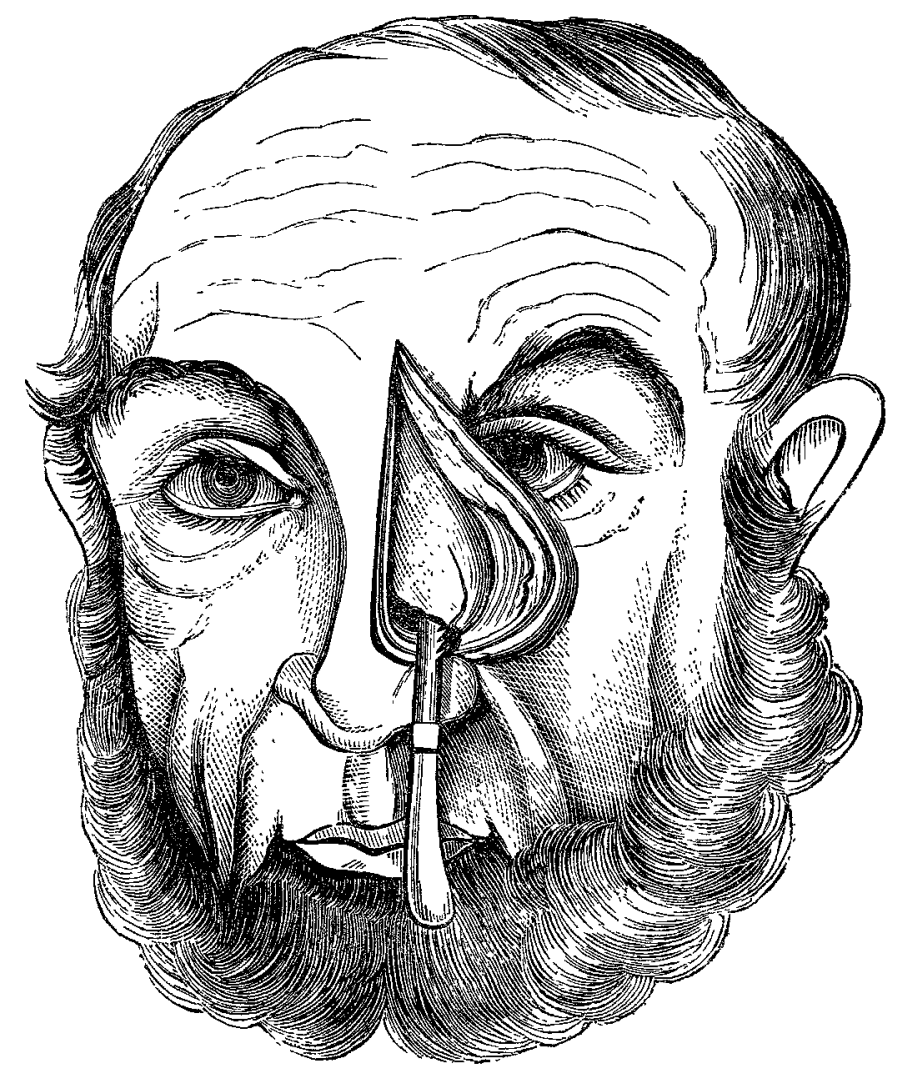

interference; and this being so I should not hesitate to perform the same operation again at a proper opportunity,

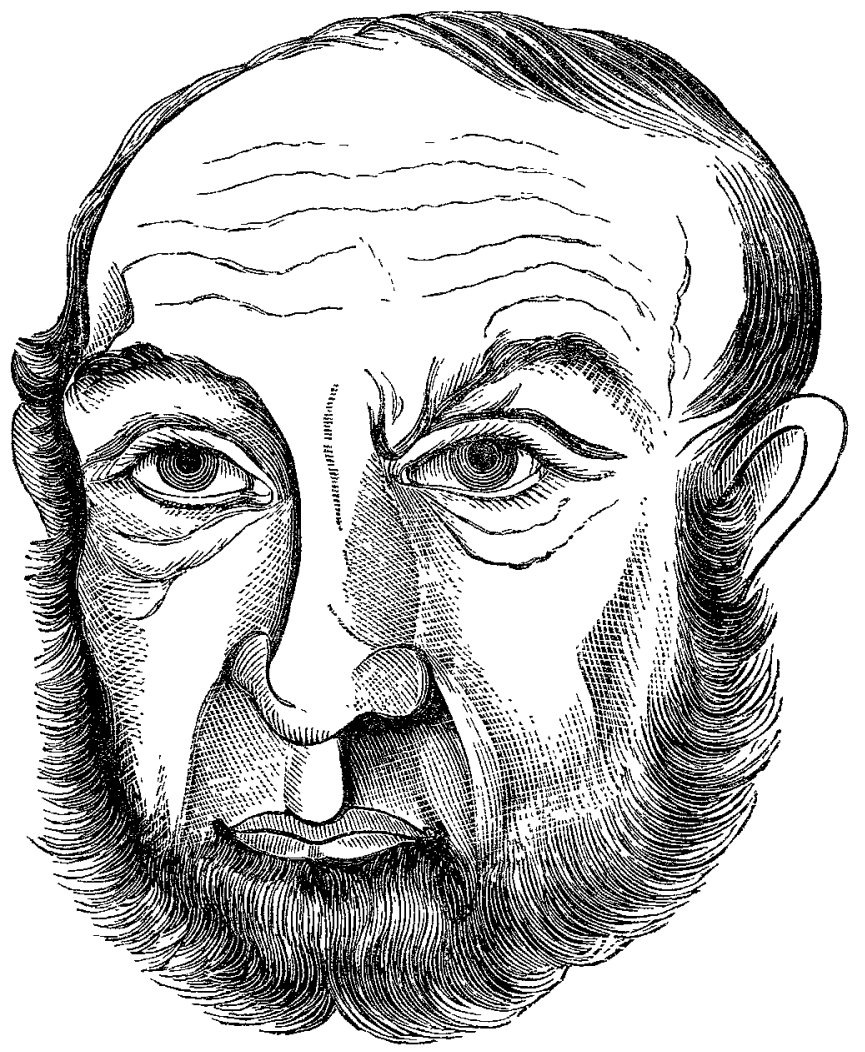

and I should be still more gratified to hear that other surgeons also have tried this ingenious operation of Professor von Langenbeck in suitable cases.

Finsbury-square.

Royal College of Surgeons of Engrand. Of the ten candidates admitted to the final examination for the Fellowship of the College last week, four were unsuccessful. 